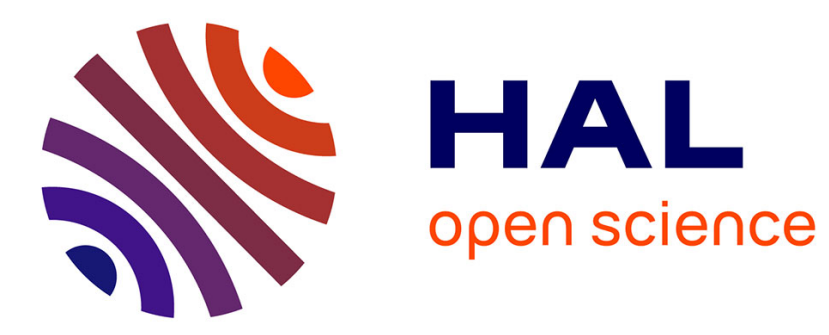

\title{
Development of a three-dimensional icing simulation code in the NSMB flow solver
}

Dorian Pena, Yannick Hoarau, Éric Laurendeau

\section{To cite this version:}

Dorian Pena, Yannick Hoarau, Éric Laurendeau. Development of a three-dimensional icing simulation code in the NSMB flow solver. International Journal of Engineering Systems Modelling and Simulation, 2016, 8 (2), 10.1504/IJESMS.2016.075544 . hal-02289588

\section{HAL Id: hal-02289588 \\ https://hal.science/hal-02289588}

Submitted on 11 Jan 2021

HAL is a multi-disciplinary open access archive for the deposit and dissemination of scientific research documents, whether they are published or not. The documents may come from teaching and research institutions in France or abroad, or from public or private research centers.
L'archive ouverte pluridisciplinaire $\mathbf{H A L}$, est destinée au dépôt et à la diffusion de documents scientifiques de niveau recherche, publiés ou non, émanant des établissements d'enseignement et de recherche français ou étrangers, des laboratoires publics ou privés. 


\title{
Development of an icing simulation code in the NSMB flow solver
}

\author{
Dorian Pena - Éric Laurendeau - Yannick Hoarau
}

June 25, 2014

\begin{abstract}
An icing model is developed in the NSMB (Navier-Stokes Multi-Block) compressible solver. The code implemented in this study is based on an Eulerian formulation for droplets tracking solved implicitly by means of CGSTAB or SIP methods, a modified iterative Messinger model using an improved water runback scheme for ice thickness calculation and three-dimensional mesh deformation to track the ice/air interface through time. The whole process is parallelized with MPI for complex multi-block configurations. The validated on several test cases including NACA23012 and NACA00012 airfoils and ONERA-M6 swept wing. Pressure coefficient around iced 23012 airfoil is compared with experimental data. Rime icing is computed on a DLR-F6 wing/body configuration. In all studied cases, the results are in good agreement with the literature.
\end{abstract}

Keywords: Aircraft Icing, Eulerian Droplet Transport Equations

\section{Nomenclature}

\section{Introduction}

Statistics establish that icing and its effects remain one of the main cause of flight accidents. The modification of geometry induced by accreted ice results in large aerodynamic performance degradation. Numerous wind tunnel experiments on iced wings establish a loss of lift, a decrease of stall angle and an increase of drag. The accreted ice eventually breaks and impacts components such engines or fuselage. Anti-icing equipment as well as antennas and Pitot tubes must be particularly well designed to avoid any icing effect.

The combination of time and cost constraints with a more and more demanding certification process has conducted the development of icing simulation tools.

Icing codes are commonly based on inviscid panel or Euler methods to simulate the fluid, a Lagrangian formulation to predict the trajectories of water droplets and impingement areas, and a classical Messinger Model to compute the ice thickness. It is evident that a full fluid solution provided by a Navier-Stokes solver in combination with turbulence model would results in more accurate icing simulations. Icing codes such LEWICE3D (NASA) [1],CANICE2D-NS [2] (École Polytechnique Montréal),ONERA3D (ONERA) [3] and FENSAP-ICE (McGill University) [4] were developed for that matter.

Lagrangian approach for droplets tracking solves Newton equation of motion for each individual droplet by means of Runge-Kutta integration. This approach requires non-automatic and well defined initial positions and amount of incoming droplets to obtain accurate impingement areas. 
Bourgault et al. [5] developed in FENSAP-ICE an Eulerian model for droplets tracking . In this PDE-based formulation, droplet volume fraction and velocity field are solved in the whole computational domain. Solving droplets equation on the same computational grid permits straightforward integration with flow solver.

The key element of ice accretion is the determination of impingement collection efficiency. While a Lagrangian formulation requires a statistical averaging process to evaluate it, the determination of this quantity in Eulerian formulation is direct. In addition, the resolution of droplet equations in the Eulerian frame open up access to the large panel of computational fluid dynamics accelerating techniques. For reasons stated above, the advantages of choosing Eulerian framework are obvious.

In FENSAP-ICE, droplet equations are solved on computational grid by means of weak Galerkin finite element method and implicit time marching using GMRES [5]. Eulerian model for droplets tracking in finite volume formulation have been investigated in many studies $[6,7,8,9]$, most of the approaches presented in these papers solve equations explicitly by means of Multi-Step Runge-Kutta integration.

Depending on the airflow temperature and velocity, impinging water droplets on the airfoil surface fully freeze on impact (rime ice conditions), or freeze partially (glaze ice conditions). In glaze type conditions, the remaining liquid water flows on the body surface as runback and eventually freezes downstream where surface temperature is below freezing point.

Ice shape computation relies on mass and energy conservation. The so-called Messinger Model [10] predicts in each control volume located on the body surface the ice accumulation, the liquid water runback mass rate and the surface temperature. The conservation equations are solved in a serial way starting from the stagnation point to the trailing edge on the upper and the lower part of the airfoil. Inflow liquid water runback in the adjacent control volume is equalized with outflow liquid water runback of current control volume. This model is currently used in many ice accretion codes such NASA LEWICE [11],LEWICE3D, CANICE2D-NS, ONERA, TRAJICE(DERA),CIRA.

According to our knowledge, only two PDE-based approaches for ice thickness computation were developed. The PDE-based formulation developed by Myers [12] takes into account the water film height as an additional property to the classical Messinger runback model. In the PDE model developed in FENSAP-ICE [13], the velocity of the runback water flowing on the surface is taken into account as well, allowing three dimensional icing computation in an unsteady fashion.

A non-PDE extension of the classic Messinger runback scheme to three dimension was proposed by [14]. In that formulation liquid water film runback direction is mainly determined by the friction direction.

Comparison of PDE-based formulation with classic quasi-steady Messinger approach on experimental wind tunnel test in glaze ice conditions do not showcase dramatic improvements for either one. Physics of glaze ice accretion remains extremely complex and icing codes nowadays are only able to obtain qualitative results in such icing conditions.

In this paper we present the icing code developed in the structured compressible and multi-block Navier-Stokes solver NSMB [15].

Supercooled water droplets field and impingement areas are obtained by means of an Eulerian approach solved implicitly using solvers BiGSTAB or SIP. The ice thickness is calculated based on an iterative Messinger model upgraded by an improved water runback scheme for threedimensional and multi-block ice accretion simulations. Mesh deformation is used to track the ice/air interface through time for multi-steps calculations.

The whole process is solved on the same mesh used for the fluid computation and parallelized with Message Passing Interface for complex multi-block configurations. Global overview of module interactions in NSMB is shown on Figure 1. 
Droplet and ice thickness modules are presented in Sect. II and validated on several test cases including NACA23012 and NACA00012 airfoils in Sect. III.A and an ONERA M6 wing in Sect. III.B.

Collection efficiency and rime ice accretion are computed on a Wing / Body DLR-F6 configuration in Sect. III.C.

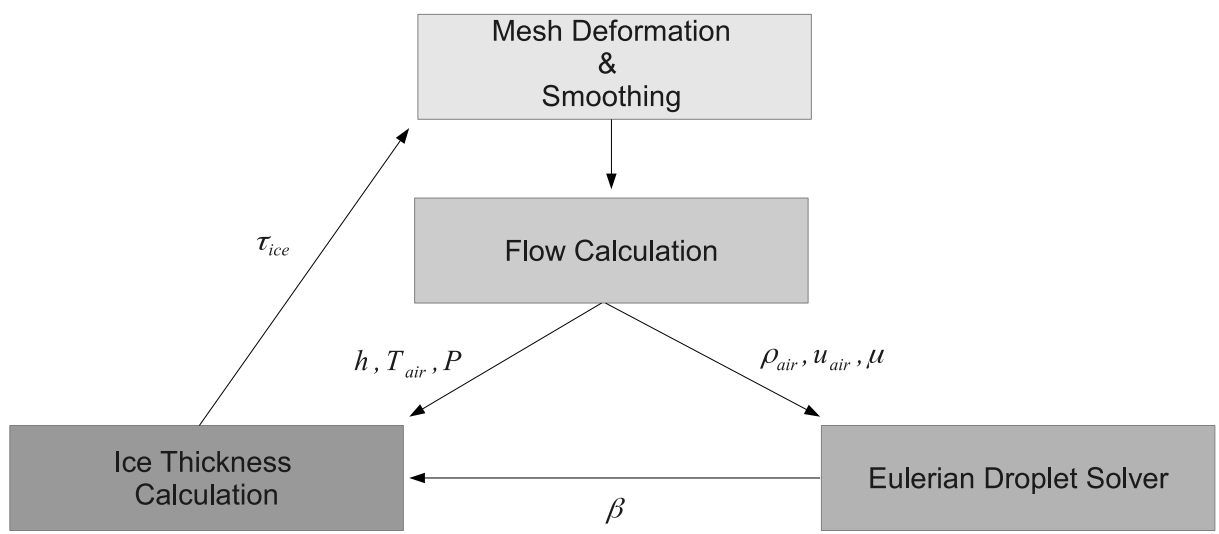

Figure 1: Module Interactions in NSMB

\section{Numerical method and governing equations}

\section{A Modeling of Droplet Field}

An Eulerian approach is developed for modeling droplet trajectories and impingement on a solid structure. The Eulerian model solves a droplet velocity field and a volume fraction distribution in the whole computational domain. Droplets are considered sphericals, with constant diameter and not to be subject to deformation or breaking. The droplet phase is sufficiently diluted to neglect interactions between droplets. Temperature of the droplet phase is set to be constant and equal to free-stream temperature, heat transfer with the surrounding air is neglected. The only forces acting on droplets are drag, gravity and buoyancy.

The governing equations for the conservation of mass and momentum of the droplets are written as follows [5] :

$$
\left\{\begin{array}{l}
\frac{\partial \alpha}{\partial t}+\nabla \cdot(\alpha \mathbf{u})=0 \\
\frac{\partial \alpha \mathbf{u}}{\partial t}+\nabla \cdot(\alpha \mathbf{u} \otimes \mathbf{u})=\alpha \frac{C_{D} R e_{d}}{24 K}\left(\mathbf{u}_{a}-\mathbf{u}\right)+\alpha\left(1-\frac{\rho_{a}}{\rho}\right) \frac{1}{F r^{2}} \mathbf{g}
\end{array}\right.
$$

$\alpha$ is defined as the non-dimensionalized volume fraction of water and $\mathbf{u}$ the non-dimensionalized velocity field of droplets. $\mathbf{u}_{a}$ is the non-dimensionalized velocity of air, $\rho$ the density of water, $\rho_{a}$ the density of air, g the gravity vector. $F r=U_{\infty} / \operatorname{sqrt}(L g)$ is the Froude number, $U_{\infty}$ the freestream speed of air, $L$ the characteristic length (typically the airfoil chord length), $K=\rho d U_{\infty} / 18 L \mu$ is an inertia parameter and the dynamic viscosity of air, $d$ is the median diameter of the droplets. The first term on the right-hand-side of the momentum equation accounts for the drag acting on the droplet or particle based on low-Reynolds number behaviour for spheres. The droplets Reynolds number $\left(R e_{d}\right)$ is defined based on the slip velocity between 
the air and droplet and the droplet diameter.

$$
R e_{d}=\frac{\rho d\left|\mathbf{u}_{a}-\mathbf{u}\right| U_{\infty}}{\mu}
$$

The drag coefficient of the droplets $C_{d}$ is given by :

$$
\left\{\begin{aligned}
C_{d} & =\frac{0.44}{R e_{d}}, \text { if } R e_{d}>1000 \\
C_{d} & =\frac{24}{R e_{d}}, \text { if } R e_{d}<0.1 \\
C_{d} & =\frac{24 \times\left(1+0.15 \times R e_{d}^{0.657}\right)}{R e_{d}}
\end{aligned}\right.
$$

For modeling the capture of incoming droplets on body surface, boundary conditions evolves during the iterative resolution such that Neumann boundary conditions are applied when the incoming droplet flux is positive or Dirichlet boundary conditions otherwise.

$$
\left\{\begin{array}{l}
\text { u.n }<0, \text { Impingement, Neumann } \mathrm{BC}: \frac{\partial u}{\partial n}=0, \frac{\partial \alpha}{\partial n}=0 \\
\text { u.n }>0 \text {, No Impingement, Dirichlet } \mathrm{BC}: \mathbf{u}=0, \alpha=0
\end{array}\right.
$$

The freestream values of droplet velocity and volume fraction are imposed as far field boundary conditions. Freestream volume fraction is set equal to $\alpha_{\infty}=1$ and droplet velocity vector equals to air freestream velocities.

The ability of the configuration to capture incoming droplets on solid walls is defined by the collection efficiency $\beta$, employing the non-dimensionalized formulation for droplet velocities and volume fraction defined above, the impingement efficiency factor writes :

$$
\beta=\alpha \mathbf{u} . \mathbf{n}
$$

A multi-block strategy paralelized with MPI is implemented for exchange of droplet state-vector values at block connectivity boundaries. The equations are treated as a generic transport problem for structured grids and recast in a finite volume form. A first order Upwind differencing Scheme (UDS) is used to evaluate the convective fluxes at interfaces. A blending Central Scheme/UDS scheme was implemented as well but causing convergence stability issues. A First order forward Euler scheme is employ to discretize the time derivative term allowing implicit resolution of the equations.

After residual linearisation, the following matrix system is obtained :

$$
\left(\frac{V}{\Delta t}+\frac{\partial \mathbf{R}}{\partial \mathbf{u}}\right) \frac{\left(\mathbf{u}^{n+1}-\mathbf{u}^{n}\right)}{\Delta t}=-\mathbf{R}^{n}
$$

Explicit terms are moved to the residual in the right-hand-side of the equation. Implicit boundary conditions are applied depending the droplet flux direction and system is solved. For memory requirements in case of large configurations, the sparse matrix obtained is inverted by iterative methods. Two algorithms have been implemented with success : the Stone's Method (Strongly Implicit Procedure) based on an incomplete LU decomposition and the biconjugate gradients stabilized method (CGSTAB). Convergence behaviour for both algorithms is almost identical but shows a slight improvement on CPU-time in favor of the CGSTAB method.

\section{B Modeling of Ice Thickness}

Ice thickness computation is based on mass conservation and energy conservation as stated by laws of thermodynamics. The so-called classic Messinger model solves the mass and energy conservation in control volumes located on surface body. The classic runback model consider inflow mass rate of liquid water in adjacent control volume equal to the outflow mass rate of 
runback liquid water film in the current control volume. This model need to be modified for three dimensional icing cases and multiblock grids. A modified iterative Messinger model is presented in this section.

The energy and mass flow rates conservation in control volume writes :

$$
\left\{\begin{array}{l}
\dot{m}_{\text {impinging }}+\sum \dot{m}_{\text {inflow }}-\dot{m}_{\text {ice }}-\dot{m}_{\text {evap }}-\sum \dot{m}_{\text {outflow }}=0 \\
\dot{q}_{\text {impinging }}+\sum \dot{q}_{\text {inflow }}-\dot{q}_{\text {evap }}-\dot{q}_{\text {ice }}-\sum \dot{q}_{\text {outflow }}-\dot{q}_{\text {conv }}=0
\end{array}\right.
$$

$\dot{m}_{\text {inflow }}$ and $\dot{m}_{\text {outflow }}$ are respectively the inflow and the outflow mass rates of runback liquid water in the control volume. Collection efficiency $\beta$ permits the calculation of the impinging mass rate of liquid water $\dot{m}_{\text {impinging. }}$. The evaporating mass rate $\dot{m}_{\text {evap }}$ is determined by a parametric model. $\dot{m}_{i c e}$ is the resultant mass rate of ice in the control volume.

$\dot{q}_{\text {inflow }}$ and $\dot{q}_{\text {outflow }}$ are the energy rates of the runback liquid water film entering and leaving the control volume. The energy rate of impacting droplets is defined by $\dot{q}_{\text {impinging }} . \dot{q}_{\text {evap }}$ is the evaporating energy rate term. $\dot{q}_{i c e}$ is the energy per second lost by solidification of the liquid water. The main contribution in the energy balance comes from the convection term $\dot{q}_{\text {conv }}$. The heat transfer coefficient necessary for the calculation of the convection term is obtained using Kays and Crawford [16] correlation. Conductive and radiative terms are neglected as they account for low contribution in the energy balance equation [11].

Freezing fraction $f=\frac{\dot{m}_{\text {ice }}}{\dot{m}_{\text {impinging }}+\dot{m}_{\text {inflow }}}$ and surface temperature are obtained by means of Newton's iterations. A complete derivation and resolution method of equations is described in [11].

The extension to three-dimensional icing configurations requires a modification of the runback model to distinguish amount of liquid water flowing out in north-south and west-east directions. The model implemented in the present study is based on [14] and consider that the liquid water film flows in the friction direction. The amount of liquid water flowing out towards control volumes located in west-east and north-south directions is determined by the following equations, subscript $P$ denotes the current control volume :

Water runback in west/east direction :

$$
\dot{m}_{\text {outflow }, w e}=\frac{C_{f}, w e}{\left|C_{f}, w e\right|+\left|C_{f}, s n\right|} \cdot \sum \dot{m}_{\text {inflow }, P}
$$

Water runback in south/north direction :

$$
\dot{m}_{\text {outflow }, \text { sn }}=\frac{C_{f}, s n}{\left|C_{f}, w e\right|+\left|C_{f}, s n\right|} \cdot \sum \dot{m}_{\text {inflow }, P}
$$

The resolution procedure treats initially all control volumes as stagnation point by imposing a guess inflow liquid water mass rate of $\dot{m}_{\text {inflow }}=0$. The liquid water film properties are then solved iteratively by the Messinger model and the runback scheme. In such formulation the treatment of stagnation points is straightforward and should permit to handle multiple stagnation points problems that are a common feature of glaze type icing. The iterative procedure permits multiblock and parallelization implementation and is an overall improvement to classic and serial ice accretion codes. Summary of the resolution procedure is the following : $(1)$ initialize $\dot{m}_{\text {inflow }}=0$ in all control volumes , (2) compute Messinger model, (3) Compute Runback distribution and update $\dot{m}_{\text {inflow }}$ in control volumes, (4) repeat steps (2) and (3) until convergence.

By knowing the mass rate of ice in each control volume, the computation of the volume of ice $V_{i c e}$ is straightforward :

$$
V_{i c e}=\frac{\dot{m}_{i c e} d t}{\rho_{i c e} \Delta s}
$$




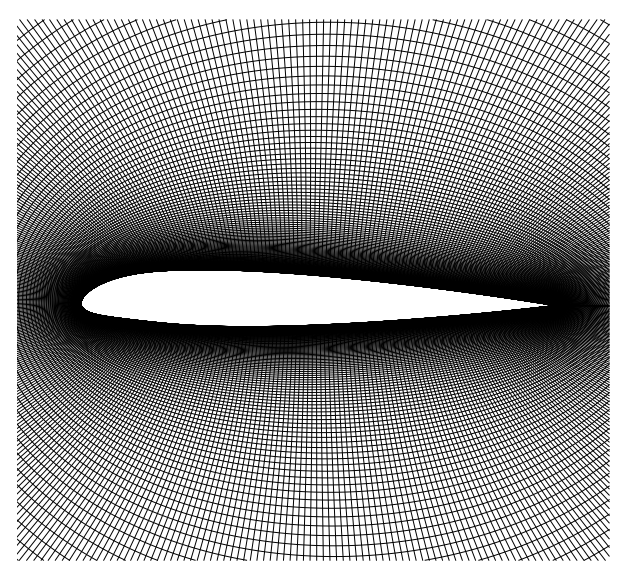

Figure 2: NACA23012 O-grid, $512 \times 258$ cells

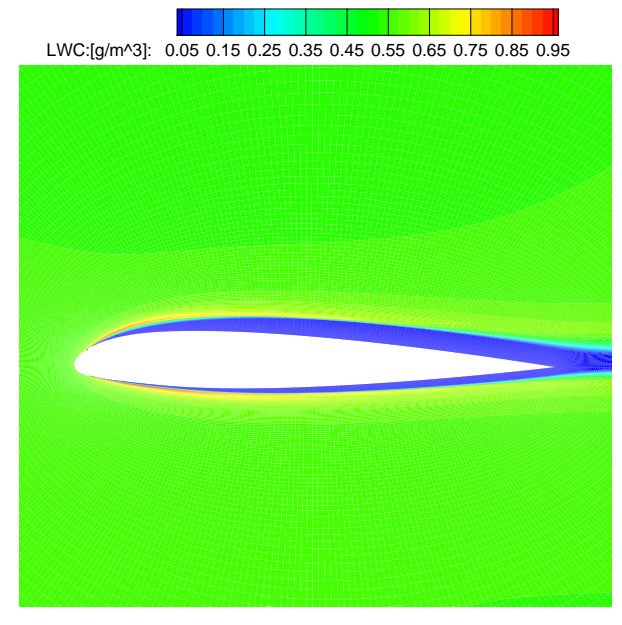

Figure 3: Case 2 - NACA23012 - Visualization of Liquid Water Content.

with $\rho_{i c e}$ the density of ice, $d t$ the icing timestep and $\Delta s$ the surface of the control volume.

The ice is considered growing in the normal direction of the surface of the control volume. Computed ice thickness $\delta$ are provided to the ALE mesh deformation algorithm available in NSMB that generates a new mesh.

\section{Results}

Simulations are performed on a two-dimensional NACA23012 \& NACA00012 aifoils, an Onera M6 swept wing and a Wing/Body DLR-F6 configuration. The flow computation is accomplished implicitly using LU-SGS method. Spatial discretization is achieved using second order or fourth order central scheme with matrix artificial dissipation. Spalart-Allmaras is used as turbulence model. Table 1 summarizes the icing cases studied.

\begin{tabular}{ccccccccc}
\hline \hline $\begin{array}{c}\text { Case } \\
\text { no. }\end{array}$ & Configuration & $\begin{array}{c}\text { AOA } \\
{\left[{ }^{\circ}\right]}\end{array}$ & Mach & $\begin{array}{c}\text { Reynolds } \\
{\left[\times 10^{6}\right]}\end{array}$ & $\begin{array}{c}T \\
{[K]}\end{array}$ & $\begin{array}{c}d \\
{[\mu \mathrm{m}]}\end{array}$ & $\begin{array}{c}L W C_{\infty} \\
{\left[\mathrm{g} / \mathrm{m}^{3}\right]}\end{array}$ & $\begin{array}{c}\text { Icing time } \\
{[\mathrm{s}]}\end{array}$ \\
\hline \hline & & & & & & & & \\
1 & NACA23012 & 2.0 & 0.24 & 12.60 & 247.85 & 30 & 0.55 & 600 \\
2 & NACA23012 & 2.0 & 0.32 & 16.23 & 252.45 & 15 & 0.30 & 1200 \\
3 & NACA00012 & 4.0 & 0.32 & 4.44 & 262.04 & 20 & 0.55 & 65 \\
4 & ONERA M6 & 6.0 & 0.15 & 2.167 & 263.15 & 20 & 1.0 & $/ /$ \\
5 & DLR-F6 & 0.0 & 0.19 & 3.172 & 249.15 & 14.5 & 0.55 & 120 \\
\hline
\end{tabular}

Table 1: Icing Cases Studied 


\section{A Two-Dimensional Configurations}

\section{A.1 Rime Ice Accretion Simulation}

Rime icing is simulated on a two-dimensional NACA23012 airfoil and compared with experiments of Broeren et al. [17] The choice of these particular validation cases was motivated by comparing our numerical results with recent high fidelity experimental ice shapes.

The O-grid generated by NS-GRID software (citation) is shown in Fig. 2. The NACA23012 mesh has a chord of $c=1.828 \mathrm{~m}$ and contains $512 \times 256$ cells divided into two blocks. The parameters of the simulations ( Cases 1 \& 2) are summarized on Table 1.

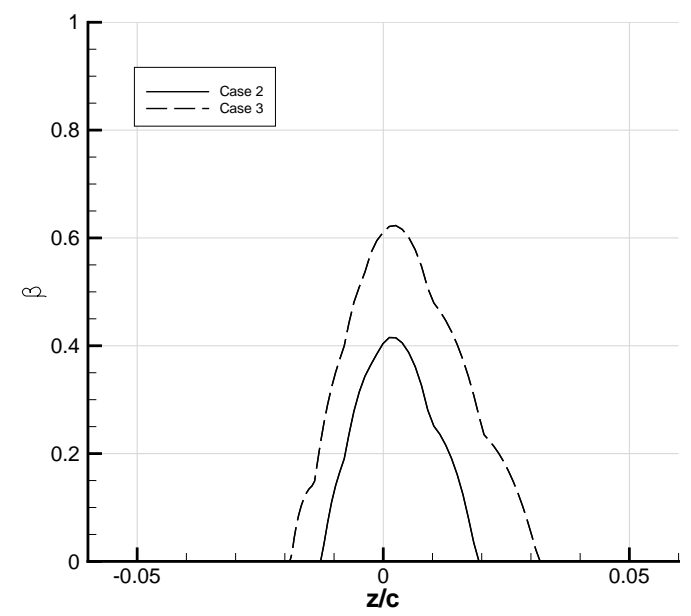

Figure 4: Case 1 \& Case 2 - NACA23012 - Collection Efficiency distribution

Visualization of Liquid Water Content distribution for case 2 is shown in Fig. 3. Shadow zones observed evince dried areas where liquid water content is nearly zero. The Collection efficiency curves are shown in Fig. 4. Ice shapes obtained after a single icing step are compared with experimental results in Figs. 5 and 6. The simulated ice shapes are in good accordance with experimental data. Taking into account a corrected angle of attack and a droplet size distribution to simulate the spray is expected to provide more precise results on the upper impingement limit where a slight underestimation of the ice thickness is obtained.

In addtion, flow is simulated on clean and automatically deformed mesh for case 2 at an angle of attack of $\mathrm{A} O A=11.9^{\circ}$, a Mach Number of $\mathrm{M} a=0.20$ and a Reynolds number of $\mathrm{Re}=16.1 \times 10^{6}$. Pressure Coefficients are compared for both clean and iced configurations with experimental data in Fig. 7. Pressure coefficient is highly increased at location where ice is accreted resulting in leading edge stall. A separation bubble occurs in the vicinity of the accreted ice as well as a flow reattachment downstream. Comparison of results from Fig. 7 showcases the validity of present code to predict aerodynamic behavior resulting from rime icing. 

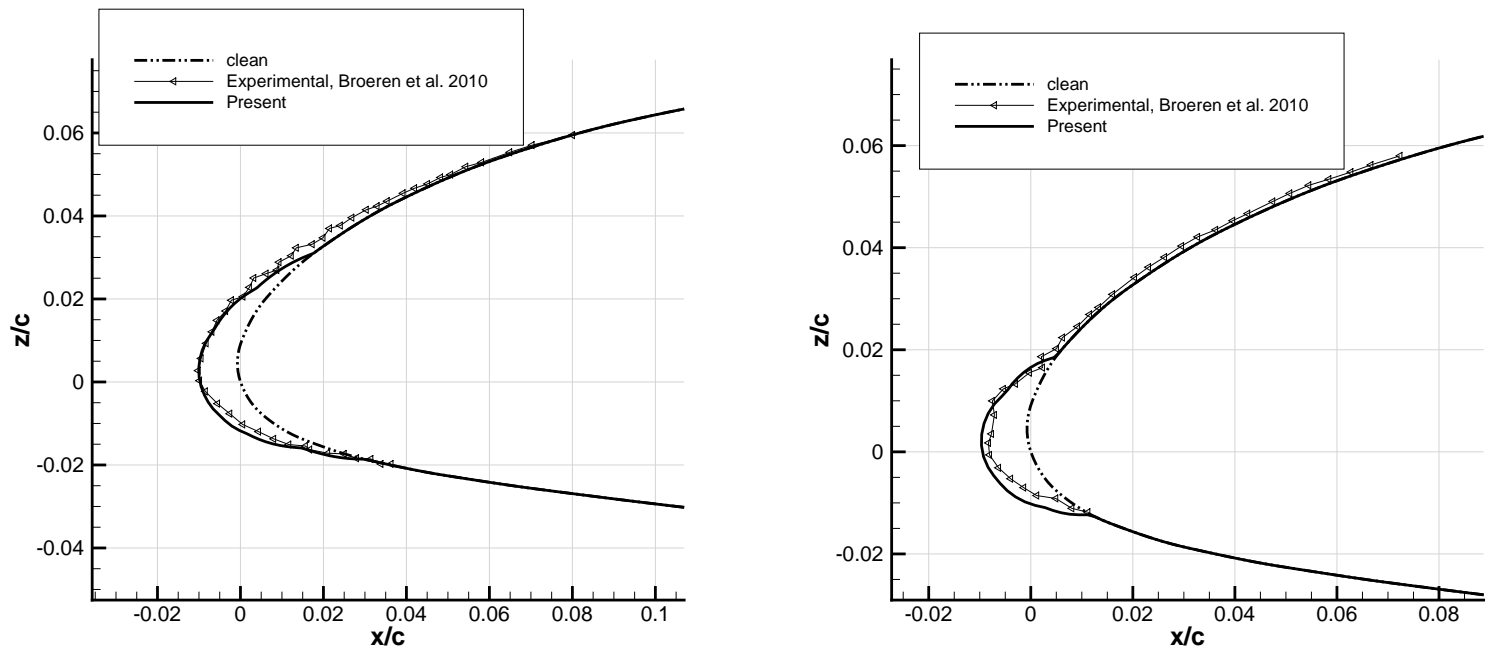

Figure 5: Case 1 - NACA23012 - Comparison of ice Figure 6: Case 2 - NACA23012 - Comparison of ice shape with experimental data of Broeren et al. shape with experimental data of Broeren et al.

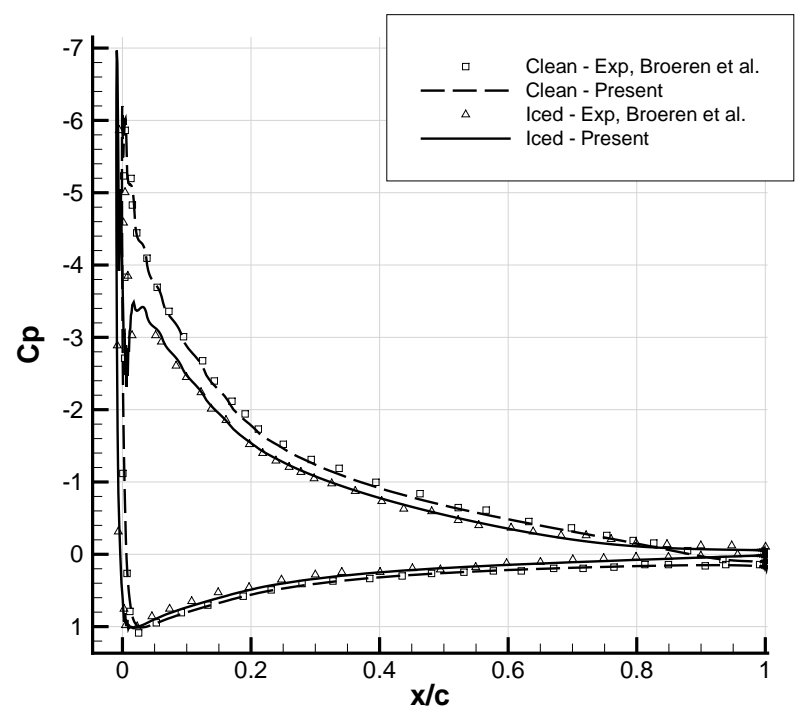

Figure 7: Case 2 - NACA23012 - Comparison of pressure coefficient with experimental data for clean and iced airfoils $-\mathrm{Ma}=0.20, \mathrm{Re}=16.1 \times 10^{6}, A O A=11.9^{\circ}$.

\section{A.2 Glaze Ice Accretion Simulation}

Glaze icing is simulated on a two-dimensional NACA00012 airfoil and compared with LEWICE [18]. Numerical Results of LEWICE were obtained by means of a panel method to simulate the flow, a Lagrangian formulation for droplet tracking, a boundary layer method to evaluate the 


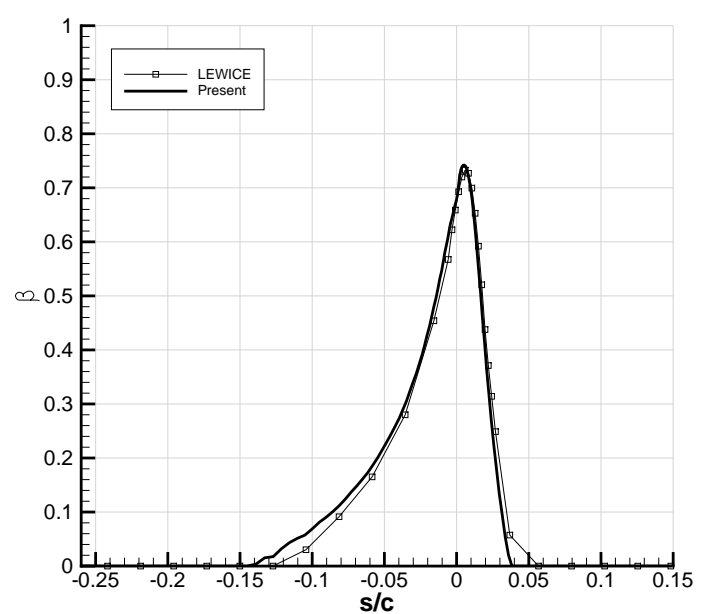

Figure 8: Case 3 - NACA00012 - Comparison of collec- Figure 9: Case 3 - NACA00012 - Comparison of ice tion efficiency with LEWICE.

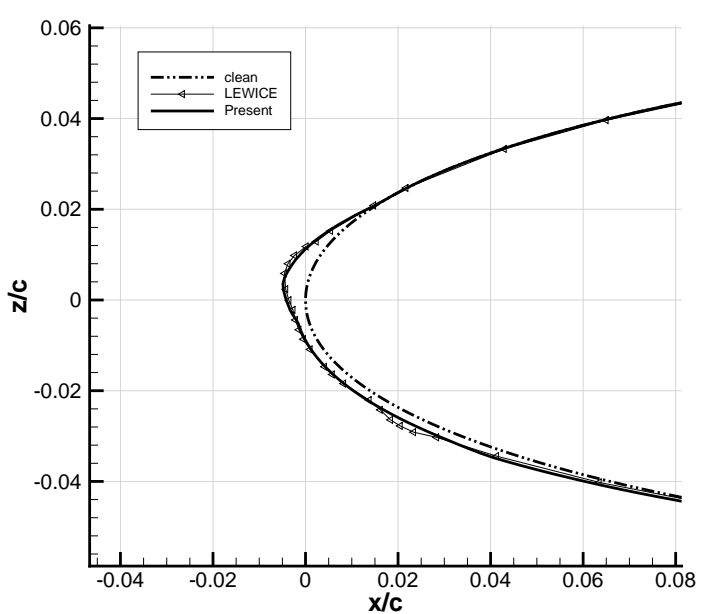
shape with LEWICE.

heat transfer coefficient and a classic Messinger model to compute the ice thickness.

The O-grid mesh generated by NS-GRID has a chord of $c=0.5334 \mathrm{~m}$ and contains $256 \times 128$ cells. The sand grain roughness used in the computation is set to $k_{s}=5 \mathrm{~mm}$. Results of impingement efficiency distribution along the airfoil surface is shown on Fig. 8. Present results showcase a higher value of the lower impingement limits and a slight increase of peak value of collection efficiency. These observations are in accordance with results of several studies of the Eulerian droplet model $[7,5]$. The calculated glaze-type ice shape is compared with LEWICE in Fig. 9 after a single icing step. A Horn forms on the upper part of the airfoil in accordance with results of LEWICE. However a discrepancy is observed on the lower part of the ice shape where a secondary horn start to form in LEWICE results while the ice thickness remains smooth in present results.This difference likely account for the different Messinger-based models used in both simulations. Test case was repeated on a NACA00012 extruded mesh. Identical results were obtained along wing span validating the three-dimensional implementation.

\section{B Onera M6 Swept Wing}

Droplet transport equations are solved on an Onera M6 swept Wing. Impingement distribution is compared with results from Sang et al. [19]. The wing has a span of $1 \mathrm{~m}$ and a mean aerodynamic chord of MAC $=0.53 \mathrm{~m}$. The structured mesh used contains approximately 884000 cells and is shown in Fig. 10. The grid is available on CFL3D validation website http://cfl3d . larc.nasa.gov/Cfl3dv6/cfl3dv6_testcases.html. Flow is computed at an angle of attack of $A O A=6^{\circ}$, a freestream velocity of $U_{\infty}=50 \mathrm{~m} / \mathrm{s}$ and a temperature of $T=263.15 \mathrm{~K}$. Icing parameters are droplet diameters of $d=20 \mu \mathrm{m}$, a liquid water content of $L W C=1 \mathrm{~g} \cdot \mathrm{m}^{3}$.

Collection efficiency distribution on airfoil is shown in Fig. 11. Impingement efficiency gets higher as the chord gets smaller which results in spare accreted ice close to the tip. This phenomena is a common result for swept wings [20]. Impingement curves are plotted on sections $1 \& 2$ respectively at $60 \%$ and $90 \%$ of span length and compared with Sang et al. in Fig. 12 . Results from Sang et al. were obtained by means of an Euler Flow Solver and a Lagrangian method for droplets tracking and do not include impingement limits of collection efficiency. Comparison with our results showcases a global good agreement. 


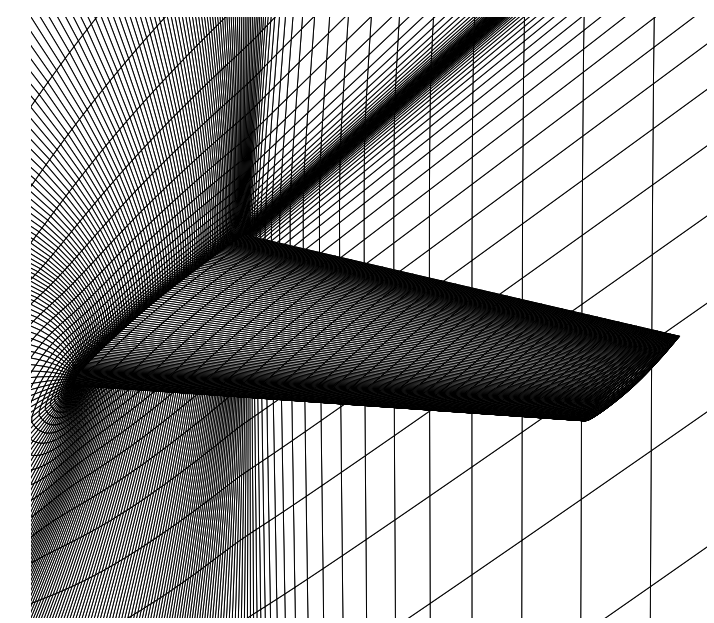

Figure 10: Case 4 - ONERA M6 - Visualization of the grid.
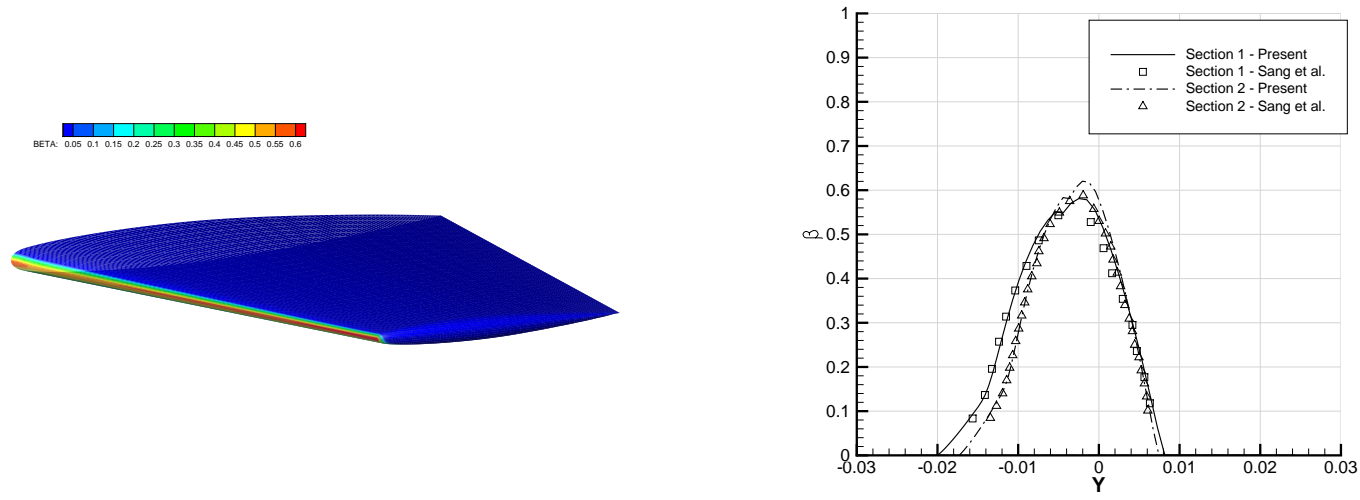

Figure 11: Case 4 - ONERA M6 - Visualization of Collection Efficiency distribution.

Figure 12: Case 4 - ONERA M6 - Comparison of Collection Efficiency with results from Sang et al. on sections $1 \& 2$.

A minor deviation of results is obtained near to the stagnation point. The origin of this discrepancy is unclear but similar collection efficiency behavior with low droplet diameters using Eulerian droplet model was obtained by Kim et al. on a two-dimensional MS-317 airfoil [6].

\section{DLR-F6 Wing Body Configuration}

The last test case concerns the simulation of rime icing on a DLR-F6 wing/body configuration. The grid is available from the DPW3 Drag Prediction Workshop website http://aaac. larc.nasa.gov/tsab/cfdlarc/aiaa-dpw/Workshop3/workshop3.html. The structured mesh contains over $8.8 \times 10^{6}$ divided in 152 blocks. The mean aerodynamic chord is MAC $=0.14 \mathrm{~m}$. 

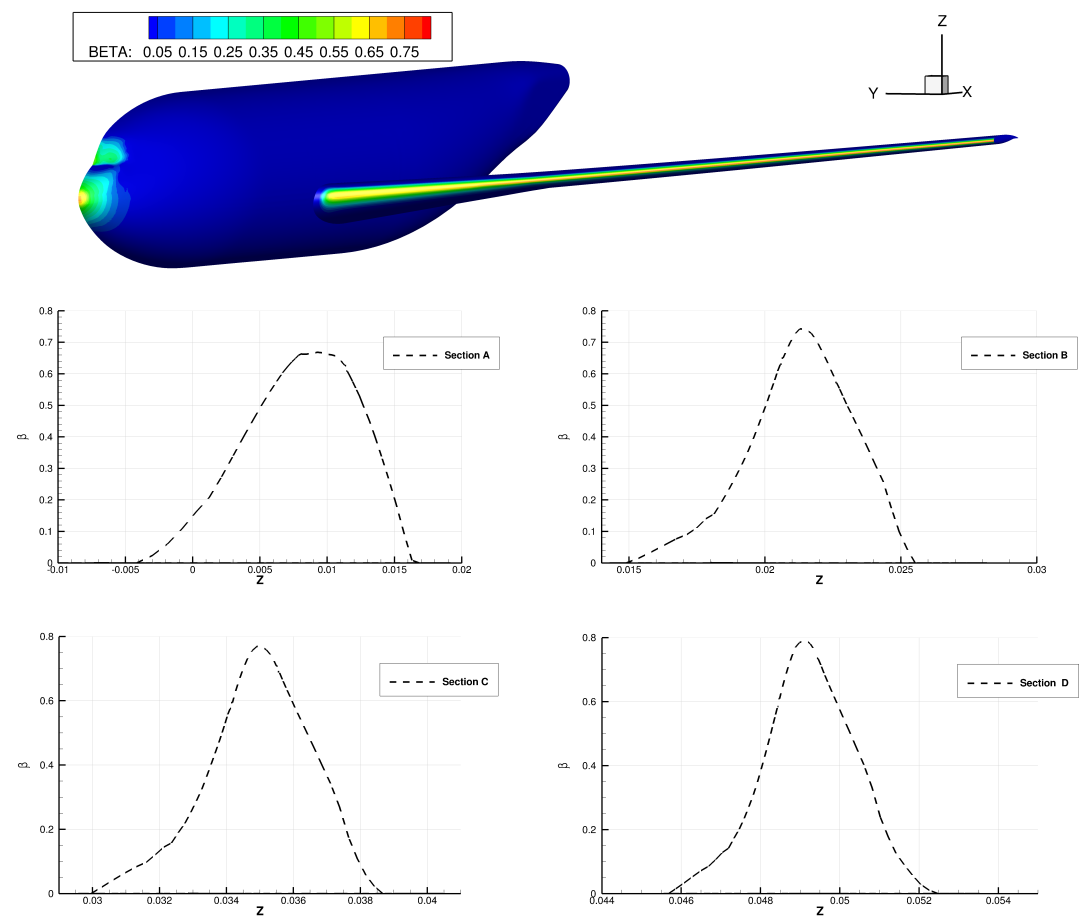

Figure 13: Case 5 - DLR-F6 - Visualization of collection efficiency on the fuselage and plot of impingement curves on sections A,B,C \& D.

The flow is simulated at a zero angle of attack, a freestream velocity of $U_{\infty}=50 \mathrm{~m} / \mathrm{s}$ and a temperature of $T=249.15 \mathrm{~K}$. The droplets diameter is equal to $d=14.5 \mu \mathrm{m}$, the liquid water content is equal to $L W C=0.55 \mathrm{~g} / \mathrm{m}^{3}$ and the exposure time equals to $t=120 \mathrm{~s}$ corresponding to rime accretion conditions.

Collection efficiency distribution is shown in Fig. 13. Impingement curves are plotted on four wing sections A,B,C,D equal to $Y=-0.1 m ;-0.25 m ;-0.4$ mand $Y=-0.55$ respectively. In accordance to results shown in Fig 12 Collection efficiency increases with decreasing chord. The disturbance induced by the body and the large wing root chord produce a shadow zone in the vicinity of the wing root causing that part of the fuselage to remain dry. These observations are in accordance with numerical results on three-dimensional Wing/Body High Lift configuration $[21]$. 

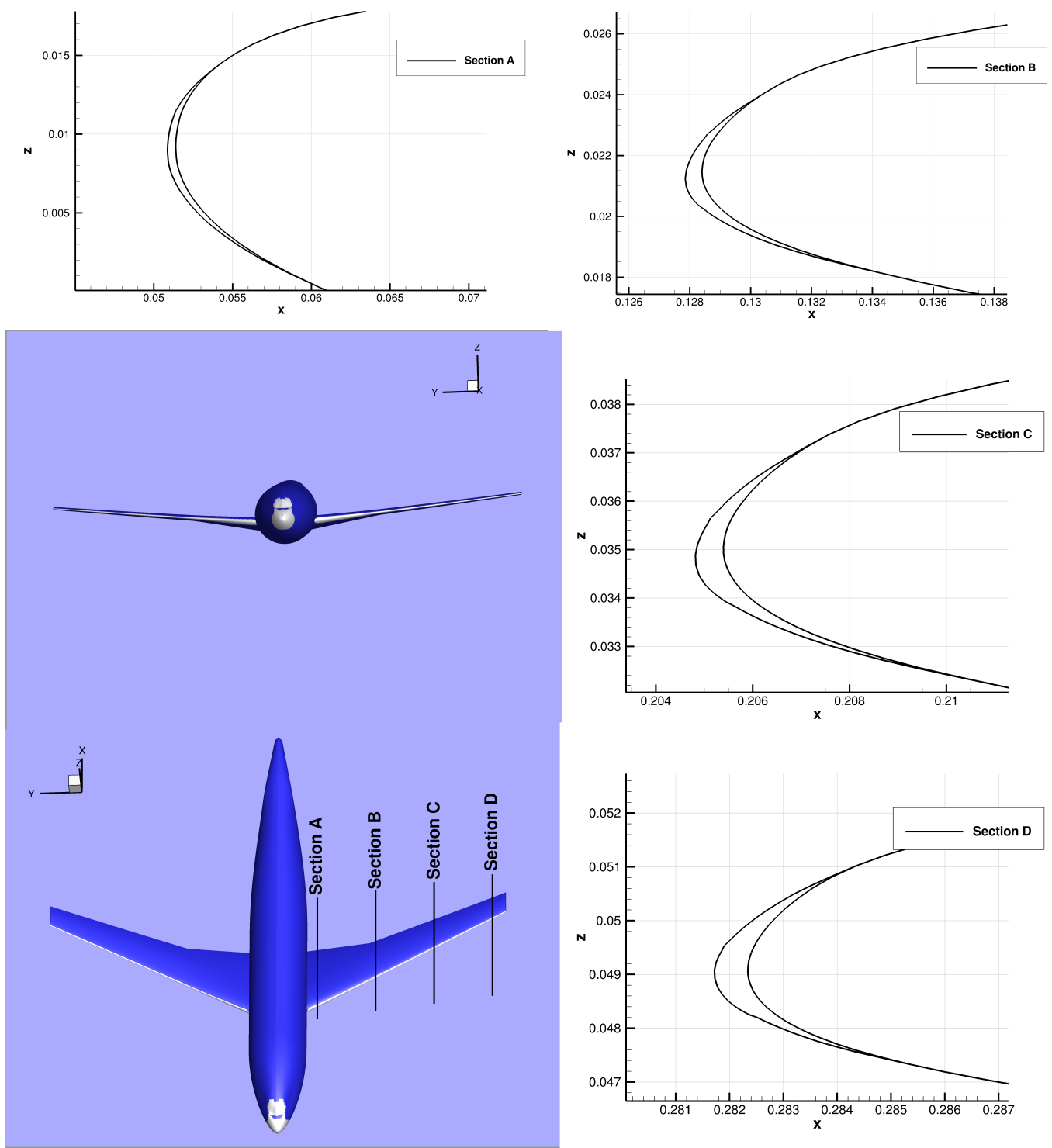

Figure 14: Case 5 - DLR-F6 - Global View of ice accretion, ice shapes on sections A,B,C \& D.

Simulated rime ice accretions are shown in Fig. 14. A global overview of icing on the geometry is displayed as well as the ice shapes on Sections A,B,C \& D. Results shows that ice only accumulates on the nose, the cockpit and the leading edge of the wing. In accordance with collection efficiency distribution, ice thickness gets higher on the leading edge near the tip indicating that anti-icing equipment must be particularly effective in that location. At the opposite, no ice accretion occurs close to the wing root leading edge. The deformed mesh at the tip vincinity is shown in Fig. 15. 


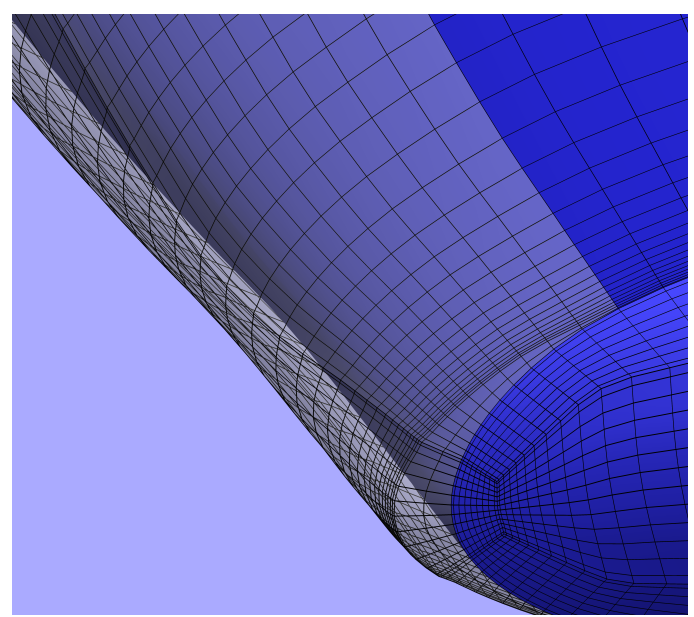

Figure 15: Case 5 - DLR-F6 - View of the deformed mesh in the vicinity of wing tip leading edge.

\section{Conclusions}

An icing code was implemented in compressible Navier-Stokes solver NSMB. The icing code developed, fully parallelized in MPI compute three-dimensional ice accretion by means of an Eulerian droplet transport model and a modified iterative Messinger model. Mesh deformation is used to track ice/air interface.

NSMB is validated with experimental and numerical data on NACA23012 and NACA0012 twodimensional configurations. Results showcase global good agreement to predict droplet trajectories and ice shape. Pressure coefficient on iced airfoil is compared with experimental data, similar aerodynamics behavior is obtained validating the methodology.

For three-dimensional validation, collection efficiency distribution is compared with numerical results on an ONERA M6 swept wing with good agreement.

Rime icing is computed of a wing/body DLR-F6, results are qualitatively in accordance with study on a wing/body High-Lift configuration.

Limitations of structured automatic mesh movement arises in complex glaze-type ice shapes. In future work, efforts will be made on this particular issue and alternative methods will be investigated.

\section{Acknowledgments}

The authors would like to thank Compute Canada for computational ressources, Kazem Hasanzadeh for grids generation and Thibaut Deloze for assistance and discussions.

\section{References}

[1] C. S. Bidwell and M. G. Potapczuk, "Users manual for the nasa lewis three-dimensional ice accretion code (lewice 3d)," 1993. 
[2] K. Hasanzadeh, E. Laurendeau, F. Saeed, and I. Paraschivoiu, "Wing aerodynamic performance analysis and stall prediction using canice2d-ns icing code," in 20th Annual Conference of the CFD Society of Canada, 2012.

[3] O. Emmanuel Montreuil, O. Arnaud Chazottes, O. Didier Guffond, O. Angelo Murrone, D.-A. Francois Caminade, and E. Stephane Catris, "ECLIPPS: 1. three-dimensional CFD prediction of the ice accretion," 2009.

[4] H. Beaugendre, F. Morency, and W. G. Habashi, "Development of a second generation in-flight icing simulation code," Journal of fluids engineering, vol. 128, no. 2, p. 378387, 2006.

[5] Y. Bourgault, W. G. Habashi, J. Dompierre, and G. S. Baruzzi, "A finite element method study of eulerian droplets impingement models," International Journal for Numerical Methods in Fluids, vol. 29, no. 4, pp. 429-449, 1999.

[6] J. Kim, P. G. Dennis, L. Sankar, and R. Kreeger, "Ice accretion modeling using an eulerian approach for droplet impingement," American Institute of Aeronautics and Astronautics, Jan. 2013.

[7] S. Jung and R. Myong, "Numerical modeling for eulerian droplet impingement in supercooled large droplet conditions," American Institute of Aeronautics and Astronautics, Jan. 2013.

[8] Y. Cao, C. Ma, Q. Zhang, and J. Sheridan, "Numerical simulation of ice accretions on an aircraft wing," Aerospace Science and Technology, vol. 23, pp. 296-304, Dec. 2012.

[9] S. Jung, R. S. Myong, and T.-H. Cho, "Development of eulerian droplets impingement model using hllc riemann solver and pod-based reduced order method," AIAA Paper, vol. 3907, p. 2011, 2011.

[10] B. L. Messinger, "Equilibrium temperature of an unheated icing surface as a function of air speed," Journal of the Aeronautical Sciences (Institute of the Aeronautical Sciences), vol. 20, no. 1, 1953.

[11] W. Wright, "Users manual for the improved nasa lewis ice accretion code lewice 1.6."

[12] T. G. Myers, "Extension to the messinger model for aircraft icing," AIAA journal, vol. 39, no. 2, p. 211218, 2001.

[13] H, lo iacute, s. Beaugendre, Fran-atilde, o. Morency, and W. G. Habashi, "FENSAP-ICE's three-dimensional in-flight ice accretion module: ICE3d," Journal of Aircraft, vol. 40, no. 2, p. 239247, 2003.

[14] C. Zhu, B. Fu, Z. Sun, and C. Zhu, "3d ICE ACCRETION SIMULATION FOR COMPLEX CONFIGURATION BASING ON IMPROVED MESSINGER MODEL," International Journal of Modern Physics: Conference Series, vol. 19, pp. 341-350, Jan. 2012.

[15] J. Vos, A. Rizzi, A. Corjon, E. Chaput, and E. Soinne, "Recent advances in aerodynamics inside the nsmb (navier-stokes multi-block) consortium," AIAA paper, vol. 802, p. 1998, 1998.

[16] W. M. Kays, M. E. Crawford, and B. Weigand, Convective heat and mass transfer. McGrawHill, 2012.

[17] A. P. Broeren, M. B. Bragg, H. E. Addy, S. Lee, F. Moens, and D. Guffond, "Effect of high-fidelity ice-accretion simulations on full-scale airfoil performance," Journal of aircraft, vol. 47, no. 1, pp. 240-254, 2010.

[18] "LEWICE Validation CD-ROM." 
[19] W. Sang, Y. Shi, and C. Xi, "Numerical simulation of icing effect and ice accretion on threedimensional configurations," Science China Technological Sciences, vol. 56, pp. 2278-2288, Sept. 2013.

[20] M. Vargas, M. Papadakis, M. Potapczuk, H. Addy, D. Sheldon, and J. Giriunas, "Ice accretions on a swept glc-305 airfoil," tech. rep., SAE Technical Paper, 2002.

[21] C. Bidwell, "Icing calculations for a 3d, high-lift wing configuration," AIAA Paper, pp. 2005-1244, 2005. 